\title{
O DESENVOLVIMENTO DA OLIVICULTURA NO RIO GRANDE DO SUL: ELEMENTOS DE FORMAÇÃO DO SISTEMA AGROINDUSTRIAL
}

\author{
Denise Saueressig ${ }^{1}$ \\ Andrea Troller Pinto ${ }^{2}$ \\ Glauco Schultz ${ }^{3}$
}

\begin{abstract}
RESUMO
Tradicional importador de azeite de oliva, o Brasil registra, nos últimos anos, o crescimento do cultivo de olivais em algumas regiões, sendo que o Rio Grande do Sul está entre os principais estados produtores. Considerando o contexto recente da atividade, ainda existem poucos estudos e pesquisas científicas realizadas na área no País. Este artigo tem o objetivo de contribuir com a geração de conhecimentos a respeito do setor e de apontar desafios e potencialidades. A pesquisa de caráter exploratório consistiu em levantamentos documentais e bibliográficos, além da consulta a dados secundários em fontes e publicações diversas. O estudo identifica os elementos que colaboraram para a estruturação da cadeia produtiva da olivicultura especialmente entre os anos 2005 e 2018. O trabalho demonstra, com o suporte dos conceitos de cadeia produtiva e sistema agroindustrial (SAG), que os empreendimentos gaúchos reúnem as condições necessárias para a manutenção do crescimento da atividade e que são justificadas por fatores como condições de solo e clima propícias, demanda de mercado e ambientes organizacional e institucional favoráveis.
\end{abstract}

Palavras-chave: Azeite de oliva, cadeia produtiva, olivais, Sul do Brasil.

\section{THE DEVELOPMENT OF OLIVE OIL PRODUCTION IN RIO GRANDE DO SUL: ELEMENTS THAT INFLUENCE THE FORMATION OF AGRO-INDUSTRIAL SYSTEM}

\footnotetext{
ABSTRACT

Traditionally an importer of olive oil, Brazil has recorded, in recent years, the growth of olive groves in some regions, with Rio Grande do Sul among the main producing states. Considering the recent context of the activity, there are still few studies and

${ }^{1}$ Graduada em Jornalismo (PUCRS). Mestrado em Agronegócios (UFRGS). Repórter na Editora Centaurus. E-mail: denise@agranja.com

${ }^{2}$ Graduada em Medicina Veterinária (UFRGS). Mestrado em Ciências Veterinárias (UFRGS). Doutorado em Tecnologia de Alimentos (UNICAMP). Professora nos cursos de graduação em Medicina Veterinária e Zootecnia (UFRGS). Professora no Programa de Pós-Graduação em Agronegócios (UFRGS). E-mail: andrea.troller@ufrgs.br

${ }^{3}$ Graduado em Engenharia Agrícola (UFPel). Mestrado e Doutorado em Agronegócios (UFRGS). Professor na Faculdade de Ciências Econômicas (UFRGS). Professor no Programa de Pós-Graduação em Agronegócios (UFRGS). E-mail: glauco.schultz@ufrgs.br
} 
scientific research carried out in the area in the country. This paper aims to contribute to the generation of knowledge about the sector and to point out challenges and potentialities. The exploratory research consisted of documentary and bibliographical surveys, as well as the consultation of secondary data in diverse sources and publications. The study identifies the elements that contributed to the structuring of the olive production chain especially between 2005 and 2018 . The study demonstrates, with the support of the concepts of productive chain and agroindustrial system (SAG), that the Gaucho enterprises meet the necessary conditions for the maintenance of the growth of the activity and that are justified by factors such as favorable soil and climate conditions, market and favorable organizational and institutional environments.

Keywords: Olive oil, olive tree, productive chain, south of Brazil.

\section{INTRODUÇÃO}

O Brasil é um tradicional importador de azeite de oliva. Nos supermercados, os consumidores estão acostumados a encontrar marcas com origem nos grandes países produtores, como Espanha, Itália, Grécia e Portugal. Os olivais são cultivados principalmente nas regiões semiáridas do Mar Mediterrâneo, onde a planta se desenvolve em condições de elevadas temperaturas e baixo volume de chuva nos meses de verão (COUTINHO et al., 2009).

Nos últimos anos, um movimento crescente de empreendedores interessados na fabricação do azeite resolveu investir no cultivo de olivais e elaborar sua própria produção no Brasil. Assim, foram formados polos em estados das regiões Sul e Sudeste. As iniciativas que surgiram, além do aporte dos empresários, contam com a colaboração de universidades, órgãos do governo e instituições de pesquisa e extensão rural.

No Rio Grande do Sul, o desenvolvimento da olivicultura foi significativo sobretudo no período entre 2005 e 2018, quando a área implantada com olivais passou de 80 hectares para 4,5 mil hectares (SCARTON, 2019). A maior parte dos olivais está concentrada na Metade Sul do Estado, em municípios como Cachoeira do Sul, Caçapava do Sul, Pinheiro Machado, Canguçu e Bagé.

A emergência de uma nova atividade e, por consequência, a diversificação da matriz produtiva, é de significativa importância para estas localidades. Com uma base tradicionalmente agropecuária, com destaque para as lavouras de arroz e a pecuária de corte, a Metade Sul do Rio Grande do Sul foi, durante muito tempo, a principal região do ponto de vista econômico, além de abrigar a maior parcela da população gaúcha (BATISTA e SILVEIRA, 2006). No entanto, foi justamente o perfil agropecuário que fez com que os municípios do Sul não acompanhassem o mesmo desenvolvimento industrial percebido no Norte e no Nordeste do Estado, fator que contribuiu para um cenário de estagnação econômica.

É possível observar uma inversão dos números relativos à participação de cada região na formação do Produto Interno Bruto (PIB) do Estado. Em 1939, conforme citam Batista e Silveira (2006), o Nordeste representava uma parcela de $33,03 \%$ do PIB, enquanto o Norte participava com $28,65 \%$ e, o Sul, com 38,33\%. Já em 2002 , os índices indicaram $53,44 \%$ para o Nordeste, $28,53 \%$ para o Norte e $18,03 \%$ para o Sul.

A evolução dos números da olivicultura no Rio Grande do Sul e, sobretudo, na Metade Sul, merece ainda mais evidência porque vem acompanhada da estruturação de uma cadeia produtiva composta por fornecedores de insumos, 
produtores, indústrias, varejo e mercado consumidor, num contexto capaz de contribuir com a movimentação econômica dos municípios. Ao mesmo tempo, agrega elementos além deste complexo vertical, como os ambientes organizacional $\mathrm{e}$ institucional, definido como sistema agroindustrial (SAG), de acordo com Zylbersztajn (2010).

A demanda de empreendedores da olivicultura por serviços, informações e tecnologias capazes de suprir carências encontradas no processo produtivo motivou - Governo do Estado do Rio Grande do Sul a investir em estratégias para fortalecimento da cadeia, num exemplo de envolvimento institucional. Entre as iniciativas que surgiram nos últimos anos está o Programa Estadual de Desenvolvimento da Olivicultura (Pró-Oliva), lançado em 2015 no âmbito da Câmara Setorial das Oliveiras, vinculada à Secretaria da Agricultura, Pecuária e Irrigação.

O trabalho da Câmara, por sua vez, foi instituído anteriormente, pelo Decreto no 49.945, de 11 de dezembro de 2012 (RIO GRANDE DO SUL, 2012). Com a participação de representantes dos governos estadual e federal, órgãos de pesquisa e extensão, além de instituições privadas, a câmara trabalha por meio de atividades como encontros regulares e simpósios técnicos para debater assuntos pertinentes ao segmento. Também são realizadas atividades de promoção e divulgação, como o Salão do Azeite Gaúcho, que expõe as marcas fabricadas no Estado em eventos como mostras agropecuárias, e a Feira do Azeite Novo, que comercializa a produção uma vez ao mês, em Porto Alegre/RS.

Diante do movimento criado nos últimos anos, cabe analisar quais os elementos que vêm colaborando para a formação de um sistema agroindustrial da olivicultura no Rio Grande do Sul, assim como indicar os desafios e potencialidades da atividade. O presente estudo descreve as principais ações propostas pelas iniciativas governamentais, traça um breve histórico do cultivo de olivais no Rio Grande do Sul e apresenta o perfil da produção atual. Com o apoio do referencial teórico que abrange cadeias produtivas, agribusiness e sistemas agroindustriais, a pesquisa utilizou dados secundários para analisar e demonstrar a relevância do processo de estruturação da olivicultura no Estado.

\section{REFERENCIAL TEÓRICO}

As mudanças nos sistemas agrícolas, especialmente na segunda metade do século $X X$ motivaram uma série de estudos sobre as operações que envolvem mais do que a produção propriamente dita, agregando as atividades a jusante e a montante do processo. O trabalho mais reconhecido é o realizado por John Davis e Ray Goldberg na Universidade de Harvard, nos Estados Unidos, em 1957.

Os dois pesquisadores, conforme citado por Batalha e Silva (2014), foram responsáveis pela criação do conceito de agribusiness, que envolve a soma de todas as operações de produção, armazenamento, processamento e distribuição, tanto de insumos quanto de produtos agrícolas e seus derivados. Assim, a atividade agrícola passa a fazer parte de uma extensa rede de agentes econômicos. Os trabalhos de Harvard tiveram "o grande mérito de deslocar o centro da análise de 'dentro para fora da fazenda', evitando tratar o setor agrícola como isolado do resto da economia (GRAZIANO DA SILVA, 1996, p.66)".

A noção de commodity system approach (CSA), ou abordagem relacionada a um sistema de commodities, é discutida em 1968, em estudo posterior de Ray Goldberg e que envolveu os sistemas de soja, trigo e laranja nos Estados Unidos. A partir desta definição, o autor passa a aplicar conceitos com origem na economia industrial, indo além do referencial teórico da matriz insumo-produto (BATALHA e 
SILVA, 2014). Os sistemas são, então, estudados com análise de estrutura-condutadesempenho (ZYLBERSZTAJN, 2010), considerando aspectos como lucratividade, estabilidade de preços, estratégia das corporações e adaptabilidade.

Observações que consideram uma cadeia de produção agroindustrial favorecem a visão global do sistema, segundo Batalha e Silva (2014). Assim, é possível perceber a importância de aprimorar a articulação entre os agentes econômicos privados, o poder público e os desejos e necessidades do consumidor.

Outra abordagem surge a partir de estudos da escola de economia francesa que levaram à criação do conceito de filière, ou cadeia, que reafirma o crescimento da interação entre as diferentes etapas do processo produtivo, desde a industrialização de insumos até a fabricação de alimentos. Ao utilizar a expressão, o autor Louis Malassis "enfatizou a sua dimensão histórica, situando o complexo agroindustrial como característico da etapa do desenvolvimento capitalista em que a agricultura se industrializa", aponta Graziano da Silva (1996, p.67).

No Brasil, termos como cadeia de produção, complexo agroindustrial e agronegócio passam a ser utilizados mais frequentemente a partir da década de 1980, num processo de reflexão teórica a respeito das transformações percebidas na produção rural do País. Trabalhos desenvolvidos desde 1990 pelo Centro de Conhecimento em Agronegócios (Pensa), da Faculdade de Economia, Administração e Contabilidade da Universidade de São Paulo (USP) estão entre as pesquisas que colaboraram para a disseminação destes conceitos nos meios acadêmico e econômico brasileiros.

Uma das propostas conceituais dos pesquisadores do Pensa refere-se ao sistema agroindustrial (SAG), que será utilizado na presente pesquisa por envolver, além dos agentes da cadeia produtiva, o ambiente institucional e as organizações de suporte relacionadas à mesma.

\section{MÉTODO}

A discussão teórica de conceitos como cadeia produtiva, agribusiness e SAG sustenta o trabalho sobre a olivicultura no Rio Grande do Sul, que é abordada no presente estudo devido à relevância do crescimento da atividade especialmente a partir de 2005. A pesquisa de caráter exploratório envolveu levantamentos documentais e bibliográficos, além da consulta a dados secundários. Foram utilizados como fontes de consulta, livros, decretos governamentais, publicações técnicas, bancos estatísticos disponíveis na internet, periódicos científicos e documentos oficiais relativos a programas de governo. Anterior à análise da cadeia da olivicultura no Estado gaúcho, o trabalho apresenta um breve panorama sobre a produção mundial e outras iniciativas desenvolvidas no Brasil.

O enfoque sobre a abordagem de sistema agroindustrial, de Zylbersztajn (1995; 2010), contribui para entender como os ambientes organizacional e institucional vêm colaborando para a estruturação da referida cadeia. O SAG é definido como "um conjunto de relações contratuais entre empresas e agentes especializados, cujo objetivo final é disputar o consumidor de determinado produto (ZYLBERSZTAJN, 2010, p.13)". O autor ressalva que embora o SAG represente um conceito mais amplo, por envolver os ambientes institucional e organizacional, a literatura de cadeias produtivas também considera aspectos institucionais.

Uma característica dos sistemas agroindustriais são as modificações que podem ocorrer ao longo do tempo, já que as relações entre os agentes podem sofrer mudanças originárias de fatores externos ou tecnológicos. As relações contratuais também podem passar por transformações e são definidas por cooperação e conflito. 
Percebe-se, ao analisar a cadeia produtiva da olivicultura no Rio Grande do Sul, que transformações vêm ocorrendo nos últimos anos, como consequência também de um sistema que ainda se encontra em estruturação por representar um complexo jovem em comparação com outras tradicionais cadeias do Estado, como a soja, a pecuária ou o arroz.

Zylbersztajn (2010) enumera os agentes que compõem o SAG para um melhor entendimento do seu funcionamento. São eles: consumidor; varejo; atacado; agroindústria e produção primária, que também engloba os fornecedores de insumos. Os ambientes institucional e organizacional representam as margens que amparam o fluxo formado pelos agentes (Figura 1).

Figura 1 - Sistema de Agribusiness e Transações Típicas

Ambiente Organizacional: Associações, Informação, Pesquisa, Finanças, Cooperativas, Firmas

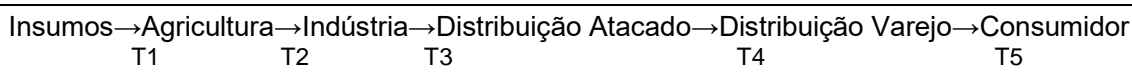

Ambiente Institucional: Cultura, Tradições, Educação, Costumes

T = Transações

Fonte: Adaptado de Zylbersztajn, 1995; 2010.

\section{RESULTADOS E DISCUSSÕES}

\subsection{OLIVICULTURA NO MUNDO}

A história da oliveira remete aos tempos bíblicos, indicando que é um dos cultivos mais antigos do mundo. Embora a literatura reconheça a dificuldade de estabelecer a origem exata da planta, há relatos de que o cultivo seja proveniente de regiões da Síria, do Líbano ou de Israel. Acredita-se que sua domesticação teve início no período Paleolítico e Neolítico, entre 10.000 e 3.000 a.C, possivelmente na Mesopotâmia, de onde foi difundida para o Egito, em 2000 a.C., e ilhas da Ásia Menor e Grécia Continental, em 1.800 a.C. (VIEIRA NETO et al., 2008).

A área cultivada com oliveiras no mundo é de aproximadamente dez milhões de hectares, sendo que $90 \%$ desse total estão na costa do Mar Mediterrâneo (JORGE e COUTINHO, 2015). A expansão do cultivo nesta região acompanhou o desenvolvimento econômico, político e cultural das civilizações locais. Mueller (2012) retrata que no terceiro milênio a.C., os lucros da venda de azeite de oliva representavam a alma de várias economias da região.

O Consejo Oleícola Internacional (COI), organização criada na Espanha, em 1959, estima que a produção mundial de azeite de oliva cresceu de cerca de 1 milhão de toneladas em 1958/1959, para 2,539 milhões de toneladas em 2016/2017. A União Europeia respondeu pela produção de 1,747 milhão de toneladas na temporada 2016/2017 e, individualmente, a Espanha produziu 1,286 milhão de toneladas. A Grécia aparece em seguida, com 195 mil toneladas, seguida pela Itália (182,3 mil t), Turquia (177 mil t), Marrocos (110 mil t), Tunísia (100 mil t), Portugal (69,4 mil t) e Argélia (63 mil t) (COI, 2017a). 
$\mathrm{Na}$ Espanha, a superfície cultivada com olivais ultrapassa os 2,5 milhões de hectares, e a região da Andaluzia responde por cerca de $70 \%$ da produção. Sanz Cañada et al. (2010) relatam que os sistemas agroalimentares formados pela atividade oleícola no país europeu, além da evidente relevância econômica, têm implicações importantes na gestão do meio ambiente e das paisagens agrárias das regiões produtoras.

Excluindo o comércio entre os países da comunidade europeia, o Brasil foi o segundo maior importador de azeite de oliva do mundo no ciclo agrícola 2014/2015 (01 de outubro de 2014 a 30 de setembro de 2015), atrás apenas dos Estados Unidos (COI, 2017b). Do total dos azeites e azeitonas em conserva consumidos no Brasil, 99\% têm origem em outros países (SCARTON, 2019).

Dados do Ministério do Desenvolvimento, Indústria e Comércio Exterior (MDIC) confirmam a forte demanda por azeite de oliva no Brasil. Para efeito comparativo, em 2005, o País importou pouco mais de 27.000 toneladas do produto. Já em 2018, foram mais de 79.000 toneladas, o equivalente a US $\$ 435,2$ milhões (BRASIL, 2019) (Tabela 1).

Tabela 1 - Importações de azeite de oliva virgem; azeite de oliva refinado; e outros azeites de oliva pelo Brasil

\begin{tabular}{lll}
\hline Período & US\$ FOB & Peso Líquido $\mathbf{( k g )}$ \\
\hline $\mathbf{0 1 / 2 0 0 5}$ a 12/2005 & 106.727 .152 & 27.008 .808 \\
$\mathbf{0 1 / 2 0 1 8}$ a 12/2018 & 435.247 .328 & 79.544 .360 \\
\hline
\end{tabular}

Fonte: Adaptado de Comex Stat, 2019.

O incremento das importações tem razões como a divulgação de benefícios da dieta mediterrânea para a saúde, a entrada de produtos no mercado interno com preços mais acessíveis e o aumento do poder aquisitivo de algumas classes sociais no País (BERTONCINI, TERAMOTO e PRELA-PANTANO, 2010). Ao definir os agentes que compõem o SAG, Zylbersztajn (2010) salienta que o consumidor é o ponto focal para onde convergem os produtos do sistema. Segundo o autor, "o consumidor moderno vem apresentando algumas mudanças que são fruto da globalização dos hábitos e padrões, preocupação com a qualidade e aspectos da saúde (ZYLBERSZTAJN, 2010, p.16)".

Ainda que as importações tenham aumentado significativamente entre 2005 e 2018, o consumo anual per capita de azeite de oliva no Brasil, entre $300 \mathrm{ml}$ e 400 $\mathrm{ml}$, é baixo quando comparado com outros países. Na Espanha e na Itália, por exemplo, os habitantes consomem cerca de 13 litros por pessoa ao ano, enquanto na Grécia, são aproximadamente 21 litros por pessoa ao ano (MUELLER, 2012), o que é um indicativo do potencial que existe para o produto no mercado interno.

\subsection{OLIVICULTURA NO BRASIL}

Além da cadeia produtiva formada no Rio Grande do Sul e que é objeto de estudo do presente trabalho, o Brasil registrou, nos últimos anos, iniciativas de cultivo de olivais e industrialização do azeite em outros estados. A estimativa do Instituto Brasileiro da Olivicultura (Ibraoliva) é de que, até 2025, o Brasil atinja em torno de 20 mil hectares implantados com olivais (SCARTON, 2019). Algumas experiências e projetos mais adiantados são relatados em microclimas favoráveis à cultura, como a Serra da Mantiqueira, em Minas Gerais e São Paulo, com altitudes maiores que 1.000 metros (BERTONCINI, TERAMOTO e PRELA-PANTANO, 2010). 
A região conta com o apoio técnico de instituições como a Empresa de Pesquisa Agropecuária de Minas Gerais (Epamig), que mantém uma Fazenda Experimental no município de Maria da Fé, onde é realizada a extração do azeite. Em São Paulo, a Agência Paulista de Tecnologia dos Agronegócios (APTA), órgão de pesquisa da Secretaria da Agricultura e Abastecimento do Estado, instituiu o projeto Oliva SP, que se dedica a estudar todas as etapas da cadeia produtiva local (BERTONCINI, TERAMOTO e PRELA-PANTANO, 2010). Em torno de 160 produtores estão envolvidos com a olivicultura na região, onde existem 40 marcas de azeite (EPAMIG, 2019).

No Paraná, além de experiências de cultivo lideradas por produtores, o Instituto Paranaense de Assistência Técnica e Extensão Rural (Emater/PR) mantém unidades de validação da oliveira em municípios como São José dos Pinhais e Salto do Lontra (PARANÁ, 2017). A Emater local estabeleceu parceria com a Empresa de Pesquisa Agropecuária e Extensão Rural de Santa Catarina (Epagri), que em 2006 implantou unidades de observação da cultura em diferentes regiões do território catarinense. Avaliações técnicas realizadas revelaram boa produtividade de frutos e bom rendimento de azeite para três cultivares (Arbequina, Arbosana e Koroneiki) plantadas em quatro localidades de Santa Catarina (DA CROCE et al., 2016).

Experiências bem-sucedidas e que resultam em produtos de alto nível vêm sendo relatadas no Brasil. Em 2013, uma pesquisa realizada pela Associação Brasileira de Defesa do Consumidor (Proteste) avaliou 19 marcas de azeite de oliva extravirgem fabricadas em diferentes países e classificou um produto brasileiro como o de melhor qualidade (SAUERESSIG, 2014). Apesar do pouco tempo de produção, alguns rótulos de fabricantes gaúchos já receberam prêmios internacionais pela alta qualidade, um diferencial importante em um mercado onde há forte concorrência com os importados (EVOOWR, 2017).

A despeito destes indicadores positivos, os especialistas observam que são muitos os desafios para a consolidação da olivicultura brasileira. São aspectos presentes desde o manejo até o controle de qualidade do produto final. Segundo Jorge e Coutinho (2015), é necessário o alinhamento entre os diferentes elos da cadeia (produtores, beneficiadores, comerciantes e consumidores) para garantir a competitividade do setor e a instituição de marcas de azeite e azeitonas de mesa genuinamente nacionais.

O apontamento de fatores que podem representar obstáculos à atividade tem gerado iniciativas que objetivam a organização do sistema desde as suas bases. Em âmbito nacional, em 01 de fevereiro de 2012, o Ministério da Agricultura, Pecuária e Abastecimento publicou a Instrução Normativa № 1 que define padrões oficiais de classificação do azeite de oliva e do óleo do bagaço de oliva. Foi a primeira legislação nacional sobre a produção e que envolve requisitos de identidade, qualidade, classificação e rotulagem (BRASIL, 2012).

Dessa forma, os dois produtos passaram a ser classificados por diferentes parâmetros e enquadrados nos seguintes grupos: Azeite de Oliva Virgem, Azeite de Oliva, Azeite de Oliva Refinado, Óleo de Bagaço de Oliva e Óleo de Bagaço de Oliva Refinado. Também passaram a ser especificados por tipo: Azeite de Oliva Extravirgem, Virgem e Lampante. Este último é considerado de qualidade inferior, com destinação não permitida diretamente para alimentação humana (BRASIL, 2012).

Esforços e iniciativas por parte de governos se enquadram nas definições retratadas por Zylbersztajn (2010) nos SAGs, onde as relações verticais ao longo das cadeias produtivas devem servir de balizador para a formulação de estratégias empresariais e políticas públicas. Batalha e Silva (2014) também consideram que a 
utilização do conceito de cadeia de produção como instrumento de formulação e análise de políticas públicas e privadas busca fundamentalmente identificar os elos fracos de uma cadeia de produção e incentivá-los através de uma política adequada. Segundo esta visão, o sucesso de uma cadeia de produção agroalimentar é o resultado do desenvolvimento harmonioso de todos os agentes que atuam na cadeia (BATALHA E SILVA, 2014, p.22).

As leis e regras também se enquadram no ambiente institucional do SAG, segundo Zylbersztajn (2010). A mudança nas organizações, diz o autor, pode ocorrer com rapidez, enquanto as instituições apresentam mudanças mais lentas. "Assim sendo, a dinâmica das empresas adapta-se ao ambiente institucional, mas também busca modificá-lo, exercendo pressões sobre o legislativo em busca de regras mais adequadas aos seus interesses (ZYLBERSZTAJN, 2010, p.20)". O autor acrescenta que a compreensão das organizações e das instituições, para a eficiência dos SAGs, é importante para definir estratégias privadas e políticas públicas.

\subsection{OLIVICULTURA NO RIO GRANDE DO SUL}

Existem registros da presença de olivais no Rio Grande do Sul no início dos anos 1800, quando a planta teria sido introduzida pelos imigrantes açorianos e, posteriormente, italianos e espanhóis. No entanto, o cultivo chegou a ser proibido pela Coroa portuguesa para que não existisse concorrência com os azeites de Portugal (COUTINHO et al., 2009). Importante destacar que o país europeu até hoje é o principal fornecedor do produto para o Brasil.

O botânico francês Auguste de Saint-Hilaire visitou o Estado em 1820 e, em seus relatos que deram origem ao livro "Viagem ao Rio Grande do Sul", descreveu na sua passagem por Porto Alegre que "plantaram-se algumas oliveiras que produziram muito bons frutos, mas em pequena quantidade (SAINT-HILARIE, 2002, p.58)". Na visita à Viamão, o botânico relatou:

As oliveiras dão muito bem nos arredores de Porto Alegre e, ali, pude comer deliciosas azeitonas; contudo, não passam de objeto de curiosidade; mas quando a população aumentar e o número de propriedades tornar-se maior, a cultura da oliveira poderá vir a ser para esta região uma nova fonte de renda (SAINT-HILARIE, 2002).

O viajante francês estava certo sobre as possibilidades produtivas do Brasil, ainda que seu prognóstico a respeito dos olivais tenha demorado a se confirmar. No final dos anos 1930, o Governo do Rio Grande do Sul importou plantas da Argentina para realizar estudos em estações de pesquisa. Já em 1948, foi criado em caráter oficial o Serviço Oleícola, órgão integrante da Secretaria da Agricultura. Algumas publicações técnicas foram lançadas e, entre os anos de 1950 e 1960, foram distribuídas cerca de 300 mil mudas em diversas regiões do Estado (RIO GRANDE DO SUL, 2015a). No entanto, a carência de base técnica, de tecnologias apropriadas e de manejo adequado são algumas das razões para insucessos na produção nas décadas seguintes.

A partir dos anos 2000, a iniciativa de empresários de diferentes ramos da economia passou a influenciar os rumos da olivicultura no Rio Grande do Sul e chamar a atenção para esta que representa agora uma alternativa de diversificação da matriz produtiva em alguns municípios, especialmente da Metade Sul do Estado. A região, com base em avaliações técnicas, reúne as melhores condições para o 
cultivo da oliveira, planta que não tolera excesso de umidade e que se desenvolve melhor quando as estações são bem definidas, com inverno frio e verão seco e quente. "O clima ideal para maturação dos frutos é o da Metade Sul do Estado, com temperaturas entre $25^{\circ} \mathrm{C}$ e $35^{\circ} \mathrm{C}$, portanto dentro da faixa de temperatura ideal para a maturação das azeitonas (WREGE, FILIPPINI ALBA e COUTINHO, 2015, p.23)".

A região está situada entre os paralelos $30^{\circ}$ e $45^{\circ}$, mesma localização de importantes países produtores. Ainda na Metade Sul, é comum a ocorrência de períodos de estiagem durante o verão, com volumes de chuva entre 400 e $500 \mathrm{~mm}$. Os índices são parecidos aos registrados nos países do Mediterrâneo, que apresentam durante o verão precipitações entre 250 e $550 \mathrm{~mm}$. Segundo Wrege, Filippini Alba e Coutinho (2015), no Rio Grande do Sul, não há falta de água para o desenvolvimento da oliveira, podendo até mesmo haver excesso na primavera, época em que ocorre o florescimento, o que pode se tornar um problema em alguns anos.

Determinações técnicas são importantes para todas as culturas agrícolas e, no caso da olivicultura, passam a ter papel fundamental num momento em que a cadeia busca consolidação e suporte para o crescimento. $O$ envolvimento de pesquisadores de instituições como Empresa Brasileira de Pesquisa Agropecuária (Embrapa), Secretaria da Agricultura, Secretaria Estadual do Desenvolvimento Rural, Pesca e Cooperativismo, Empresa de Assistência Técnica e Extensão Rural (Emater/RS), Ministério da Agricultura e universidades oferecem alicerce aos produtores que investem na cadeia. A participação de prefeituras, viveiristas, além da proatividade dos empreendedores, constituem um ambiente organizacional de importância significativa para a continuidade da evolução da cadeia.

Em 2008, devido ao aumento da demanda por informações identificadas entre os produtores, a Secretaria da Agricultura, Pecuária e Irrigação criou o Grupo Técnico de Pesquisa e Extensão em Olivicultura. A equipe, formada por engenheiros agrônomos de diferentes instituições e universidades, mantêm-se em atividade e vem publicando documentos com recomendações sobre temas de interesse dos olivicultores (JOÃO, ALMEIDA e AMBROSINI, 2017).

Em 2013, após estudos realizados entre especialistas de diferentes instituições do Brasil e do exterior, a Embrapa lançou o Zoneamento Edafoclimático da Olivicultura para o Rio Grande do Sul. A publicação é voltada a revelar as regiões com aptidão de clima e de solo para o cultivo, assim como aquelas que não reúnem as melhores condições para o desenvolvimento da planta. Embora o Estado não apresente a classe "preferencial" para a oliveira, a classe "recomendável" do zoneamento está presente em mais de 7,4 milhões de hectares especialmente nas regiões da Metade Sul e da Fronteira Oeste, que são intercalados com zonas de classe "pouco recomendável", que somam mais de 11,1 milhões de hectares (WREGE e COUTINHO, 2013).

Orientações específicas para a cultura também passaram a integrar a programação de palestras e de atividades a campo de instituições de extensão e pesquisa. Em novembro de 2016, a Embrapa Clima Temperado, com sede em Pelotas, sediou o II Encontro Estadual e a 2a Reunião Técnica Nacional de Olivicultura. Em dois dias de atividade, houve palestras com especialistas do Brasil e do exterior e uma visita técnica à uma propriedade dedicada à cultura, no município de Pinheiro Machado (ELOI, 2016).

As recomendações direcionadas à olivicultura detalham aspectos de clima, solo, manejo fitossanitário, tecnologias de propagação, instalação do olival, poda, colheita, custos de implantação e cultivares com diferentes ciclos produtivos e capazes de se adaptar às condições climáticas. Atualmente, as variedades mais 
cultivadas no Estado são Arbequina, Koroneiki, Picual, Arbosana, Frantoio, Manzanilla e Coratina (JOÃO, ALMEIDA e AMBROSINI, 2017). A cultivar Arbequina, originária da Espanha, é considerada a de maior adaptabilidade a diferentes condições de ambiente, mas seu plantio não é recomendado em solos sujeitos ao encharcamento ou com altos teores de argila (COUTINHO, JORGE e HAERTER, 2015).

Associações de produtores criadas nos últimos anos também colaboram para a organização da atividade. Alguns exemplos são a Associação dos Olivicultores do Sul do Brasil, Associação Rio-Grandense de Olivicultores e Associação Brasileira de Produtores, Importadores e Comerciantes de Azeite de Oliva. As organizações, atesta Zylbersztajn (2010), são estruturas criadas para dar suporte ao funcionamento dos SAGs, tais como: empresas, universidades, cooperativas e associações de produtores. Entre as iniciativas mais recentes de organização da atividade pode-se citar a fundação, em agosto de 2017, do Instituto Brasileiro da Olivicultura (Ibraoliva) (JOÃO, ALMEIDA e AMBROSINI, 2017), que foi criado para fortalecer o sistema em negociações conjuntas, como por exemplo, em reivindicações junto ao Governo Federal.

Em 2012, a Secretaria da Agricultura do Rio Grande do Sul criou a Câmara Setorial da Olivicultura e iniciou a realização de eventos de Abertura Oficial da Colheita em diferentes municípios. Em julho de 2015, o Governo do Estado lança oficialmente o Programa Estadual de Desenvolvimento da Olivicultura (Pró-Oliva), que é estruturado em ações de subprogramas: i) Defesa Sanitária e Produção de Mudas de Qualidade; ii) Aumento da Produção e Produtividade dos Olivais Assistência Técnica e Pesquisa; iii) Industrialização de Azeites e Conservas; e iv) Crédito - Linhas de Financiamento. Para atender ao quarto subprograma, foram firmados termos de cooperação com cinco instituições financeiras: Banco do Brasil, Banrisul, Badesul, Sicredi e Banco Regional de Desenvolvimento do Extremo Sul (BRDE). Entre as justificativas para a criação do Pró-Oliva, está descrito:

\begin{abstract}
Várias regiões do RS reúnem excelentes condições de clima e solos para projetos de novos olivais. Prova disto é o valoroso trabalho de diversos empresários rurais gaúchos e outros de fora do Estado, atraídos pelas nossas condições, que já estão colhendo frutos e fabricando azeites gaúchos de excelente qualidade (RIO GRANDE DO SUL, 2015b).
\end{abstract}

O decreto de criação do Pró-Oliva (RIO GRANDE DO SUL, 2015b) relaciona instrumentos que orientam o trabalho do programa: i) mobilização dos produtores por meio de reuniões, seminários e palestras; ii) assistência técnica aos produtores e assessoria a municípios que desenvolvam programas de olivicultura; iii) manutenção de um cadastro olivícola; iv) ações em defesa sanitária vegetal com o intuito de evitar a entrada de pragas e de doenças não presentes no Estado; v) realização de eventos de capacitação em produção para técnicos e produtores, bem como de campanhas educativas junto à sociedade visando ao esclarecimento sobre qualidade de azeites; vi) utilização e criação de linhas de financiamento para a implantação de olivais e de agroindústrias; e vii) mecanismos de adequação tributária no sentido de estimular a produção de azeite gaúcho.

Os esforços empreendidos nos últimos anos ajudaram a alavancar a olivicultura no Rio Grande do Sul. Entre os anos de 2005 e 2018, o cultivo de olivais passou de 80 hectares para cerca de 4,5 mil hectares (SCARTON, 2019). Na safra 2018/2019, foram elaborados 198.664 litros de azeite a partir de uma área de cerca 
de 1.500 hectares que se encontra efetivamente em produção (RIO GRANDE DO SUL, 2019).

Uma primeira pesquisa oficial por parte do Governo do Rio Grande do Sul, e que deu origem ao Cadastro Olivícola (JOÃO, ALMEIDA e AMBROSINI, 2017), identificou 145 produtores e a presença da atividade em 56 municípios. Este mesmo levantamento indicou a existência de três viveiros de mudas e de 20 marcas comerciais de azeite. Em 2019, o número de marcas foi atualizado para 33: Alma do Segredo, Alto dos Olivos, Batalha, Bosque Olivos, Bueno Az 0.2, Casa Alfaro, Capela de Santana, Capolivo, Casa Albornoz, Casa Gabriel Rodrigues, Cerro dos Olivais, Coimbra Martins Costa, Costa Doce, Costi Olivos, Dom José, Dona Esmeralda, Kor, La Pataca, Milonga, Nina, Olivae, Olivais da Fonte, Olivas do Seival, Olivas do Sul, Olivo Brasil, Ouro de Santana, Prosperato, Quinta da Estância, Quinta Santha Júlia, São Pedro, Terrapampa, Verde Louro e Vila do Segredo (RIO GRANDE DO SUL, 2019) (Quadro 1).

Quadro 1 - Marcas de azeite identificadas no Rio Grande do Sul

\begin{tabular}{|c|c|}
\hline Marca & Município \\
\hline Alma do Segredo & Caçapava do Sul \\
\hline Alto dos Olivos & Barra do Ribeiro \\
\hline Batalha & Pinheiro Machado \\
\hline Bosque Olivos & Cachoeira do Sul \\
\hline Bueno Az 0.2 & Candiota \\
\hline Casa Alfaro & Candelária \\
\hline Capela de Santana & Sentinela do Sul \\
\hline Capolivo & Canguçu \\
\hline Casa Albornoz & Santana do Livramento \\
\hline Casa Gabriel Rodrigues & São Gabriel \\
\hline Cerro dos Olivais & Caçapava do Sul \\
\hline Coimbra Martins Costa & Rosário do Sul \\
\hline Costa Doce & Dom Feliciano \\
\hline Costi Olivos & Caçapava do Sul \\
\hline Dom José & Caçapava do Sul \\
\hline Dona Esmeralda & São Sepé \\
\hline Kor & Glorinha \\
\hline La Pataca & São Francisco de Paula \\
\hline Milonga & Triunfo \\
\hline Nina & Rosário do Sul \\
\hline Olivae & Piratini \\
\hline Olivais da Fonte & Formigueiro \\
\hline Olivas do Seival & Candiota \\
\hline Olivas do Sul & Cachoeira do Sul \\
\hline Olivo Brasil & Dom Pedrito \\
\hline Ouro de Santana & Santana do Livramento \\
\hline Prosperato & Caçapava do Sul \\
\hline Quinta da Estância & Viamão \\
\hline Quinta Santha Júlia & Encruzilhada do Sul \\
\hline São Pedro & Caçapava do Sul \\
\hline Terrapampa & Bagé \\
\hline Verde Louro & Canguçu \\
\hline Vila do Segredo & Caçapava do Sul \\
\hline
\end{tabular}

Fonte: Adaptado de Rio Grande do Sul (2019). 
A descrição dos agentes e dos ambientes formadores da cadeia da olivicultura gaúcha permite a elaboração do esquema a seguir como forma de ilustrar o sistema (Figura 2):

\section{Figura 2 - SAG da olivicultura no Rio Grande do Sul}

Ambiente Organizacional: Embrapa, Secretaria da Agricultura do RS, Emater/RS, Ministério da Agricultura, associações de produtores, Instituto Brasileiro da Olivicultura, instituições financeiras, entre outros.

Insumos: produtores de mudas (viveiristas); fornecedores de fertilizantes,

equipamentos e defensivos

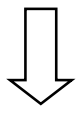

Agricultura: 145 produtores

que cultivam oliveiras

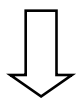

Agroindústria: 33 marcas de azeite

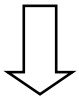

Distribuição: vendas em canais próprios, lojas especializadas e grandes redes de supermercados<smiles>C1CCCCC1</smiles>

\section{Consumidor final}

Ambiente Institucional: legislações, câmara setorial, Pró-Oliva, entre outros.

Fonte: Elaborado pelos autores e adaptado de Zylbersztajn, 1995; 2010.

A análise da olivicultura à luz da proposta conceitual de SAG permite a percepção de agentes peculiares deste sistema. Nota-se, por exemplo, que algumas empresas instaladas no Rio Grande do Sul completam o ciclo de produção. É o caso da Tecnoplanta, que fabrica a marca de azeite Prosperato. A empresa produz as mudas necessárias para o cultivo, mantém um olival próprio, industrializa a colheita e comercializa seus produtos em canais diretos de venda pela internet e na sua sede, localizada em Caçapava do Sul (PROSPERATO, 2017).

Ao mesmo tempo, atua como fornecedora de insumos, já que disponibiliza a venda de suas mudas a outros produtores. $O$ trabalho segue com assistência 
técnica, aquisição e processamento da produção dos clientes (PROSPERATO, 2017). Zylbersztajn (2010) lembra que a multifuncionalidade do espaço rural vem crescendo nos últimos anos, levando ao desenvolvimento de outras atividades de renda, e não mais apenas a agricultura. O processo, diz o autor, motiva a formação de um novo perfil do tradicional homem do campo.

A observação da cadeia, no entanto, também leva à identificação de transações tradicionais, já que existem empresas que adquirem insumos (mudas), terceirizam a fabricação do azeite e comercializam a produção em lojas especializadas e em grandes redes de supermercados. Devido às características das operações realizadas ao longo do sistema, percebe-se uma relação geralmente amistosa entre os fabricantes de azeite. Num contexto em que os equipamentos necessários à elaboração do produto final ainda são inacessíveis para parte dos empreendedores, a opção é pela terceirização dos processos em uma unidade concorrente (SAUERESSIG, 2018).

As empresas também participam de forma conjunta de atividades relacionadas ao Programa Pró-Oliva, como o Salão do Azeite Gaúcho. Batalha e Silva (2014) explicam tal interação abordando o conceito de coopetição, ou seja, quando a competição e a cooperação caminham juntas. Apesar de cada empresa manter sua própria marca no mercado, existem associações e acordos entre os concorrentes que revelam que é possível incrementar os negócios sem prejudicar os objetivos finais das outras organizações.

Também é perceptível, na análise do SAG da olivicultura gaúcha, que os ambientes institucional e organizacional atuam como importantes forças coordenadoras do sistema. Assim como assinalado por Zylbersztajn (1995), o papel do Estado é ainda mais especial quando são valorizados programas de proteção da renda, regulamentação de operações com alimentos e investimentos em pesquisa. Observa-se que o envolvimento de instituições como Embrapa, Secretaria da Agricultura e Emater vem colaborando para ampliar o conhecimento sobre o cultivo das oliveiras por meio de recomendações técnicas.

Zylbersztajn (1995) cita Goldberg, que em seus trabalhos de 1957 e 1968 analisou que as associações apoiam as firmas nos processos de adaptação necessários devido às mudanças nos sistemas agrícolas. Principalmente as pequenas empresas têm acesso limitado a informações e, assim, as organizações podem colaborar para difundir o conhecimento necessário. Respostas institucionais também são importantes num ambiente de alta instabilidade, como é o que está inserido o setor agrícola, que tantas vezes é afetado por condições climáticas desfavoráveis, oscilação de preços e mudanças nos hábitos de compra do consumidor (ZYLBERSZTAJN, 1995).

Por fim, trabalhos específicos voltados à olivicultura permitem relacionar pontos críticos que devem ser alvo de maior atenção dos agentes envolvidos no desenvolvimento da cadeia. Entre eles, o incremento de políticas públicas e estratégias empresariais voltadas a soluções para questões como a necessidade de maior envolvimento da pesquisa e difusão de conhecimentos a respeito de aspectos agronômicos da produção, o esforço pelo registro de insumos, a capacitação de mão de obra para trabalho nos pomares e as ações de educação do consumidor a respeito do produto nacional (SAUERESSIG, 2018). Sobre este último aspecto, cabe destacar que, se por um lado, alguns rótulos tenham procura intensa e sequer conseguem atender a demanda, por outro, ainda há desconhecimento do consumidor sobre a existência do azeite elaborado no Estado. 


\section{CONSIDERAÇÕES FINAIS}

A abordagem teórica e os elementos identificados na olivicultura do Rio Grande do Sul permitem analisar a atividade a partir dos conceitos de cadeia produtiva e de sistema agroindustrial. Foi possível, por meio do presente trabalho, avaliar o contexto e os elementos que colaboram para a estruturação e desenvolvimento desta cadeia ainda jovem no cenário econômico gaúcho.

A pesquisa buscou, em dados coletados sobre o setor, demonstrar que o crescimento da olivicultura nos campos do Rio Grande do Sul foi bastante significativo especialmente entre os anos de 2005 e 2018, o que expressa a relevância do presente estudo. A pesquisa documental e em dados secundários revelou um aumento expressivo na área cultivada com olivais e o surgimento de 20 marcas de azeite.

Fatores como demanda do mercado e potencial para aumento do consumo, condições de cultivo favoráveis, medidas de apoio do Governo e o envolvimento de instituições de pesquisa podem estar entre as razões para a evolução registrada nos últimos anos. Percebe-se, ao analisar a olivicultura gaúcha por meio da proposta conceitual de sistema agroindustrial (SAG), que os agentes inseridos na cadeia se beneficiam daqueles que estão às margens da estrutura, ou seja, os ambientes organizacional e institucional.

No caso de uma atividade recente quando comparada com outros segmentos da matriz produtiva do Estado, torna-se ainda mais relevante as ações e interferências propostas por instituições capazes de oferecer suporte e de auxiliar na regulação dos processos e na superação de gargalos. É o caso de atividades realizadas no âmbito da Câmara Setorial das Oliveiras, como reuniões, eventos técnicos e a própria divulgação do azeite processado no Rio Grande do Sul. Concluise que este trabalho é fundamental para a criação de leis e de regulamentações específicas, lançamento de políticas públicas, promoção do conhecimento e difusão de informações entre os produtores, assim como o estímulo ao consumidor, tão habituado a adquirir rótulos importados.

É possível identificar, por meio da descrição dos agentes formadores do SAG, que existe um esforço constante por melhorias nas diferentes etapas da cadeia de produção. O trabalho é pela resolução de pontos críticos que nos próximos anos podem determinar a sustentabilidade econômica da atividade.

Ao mesmo tempo, o estudo identifica a necessidade e pertinência de novos e aprofundados trabalhos a respeito do tema, com pesquisas que envolvam, por exemplo, a investigação mais detalhada dos pontos fortes e fracos do setor, assim como as transações entre os agentes. Por toda a evolução percebida até o momento, considera-se importante a continuidade das análises sobre as potencialidades e desafios do processo de desenvolvimento da olivicultura no Rio Grande do Sul, assim como a investigação do crescimento do setor a partir do suporte de iniciativas públicas e privadas.

\section{REFERÊNCIAS}

BATALHA, M. O.; SILVA, A. L. Gerenciamento de sistemas agroindustriais: definições, especificidades e correntes metodológicas. In: BATALHA, M. O. (Coord.). Gestão agroindustrial. 3. ed. São Paulo: Atlas, 2014. p.1-60.

BATISTA, I. M.; SILVEIRA, V. C. P. Influência das desigualdades econômicas regionais no setor agropecuário do Rio Grande do Sul. Extensão Rural, Santa 
Maria, v. 13, n.13, p.60-92, jan./dez. 2006. Disponível em: https://periodicos.ufsm.br/extensaorural/article/view/5605/3327. Acesso em: 3 abr. 2019.

BERTONCINI, E. I.; TERAMOTO, J.R.S.; PRELA-PANTANO, A. Desafios para produção de azeite no Brasil. [S.I.], 2010. Artigo em hypertexto. Disponível em: http://www.infobibos.com/Artigos/2010_4/DesafioOliva/index.htm. Acesso em: 4 jul. 2017.

BRASIL. Instrução Normativa $\mathrm{n}^{\circ}$ 1, de 30 de janeiro de 2012. Estabelece o Regulamento Técnico do Azeite de Oliva e do Óleo de Bagaço de Oliva. Diário Oficial [da] República Federativa do Brasil, Brasília, DF, 01 de fev. 2012. Seção 1, n.23.

BRASIL. Ministério da Indústria, Comércio Exterior e Serviços. Comex Stat. Exportação e Importação Geral. Brasília, 2019. Disponível em: http://comexstat.mdic.gov.br/pt/geral. Acesso em: 3 abr. 2019.

COI - CONSEJO OLEÍCOLA INTERNACIONAL. Áreas de Actividad. Economía. Importaciones por países. Madrid, 2017a. Disponível em: http://www.internationaloliveoil.org/estaticos/view/135-imports-by-selectedmarkets?lang=es_ES. Acesso em: 14 jan. 2018.

COI - CONSEJO OLEÍCOLA INTERNACIONAL. World trade in olive oil and table olives. Market Newsletter, Madrid, n. 121, nov. 2017b. Disponível em: http://www.internationaloliveoil.org/news/view/697-year-2017-news/909-marketnewsletter-november-2017. Acesso em: 14 jan. 2018.

COUTINHO, E. F. et al. Introdução e importância econômica. In: COUTINHO, E.F.; RIBEIRO, F.C.; CAPPELLARO, T.H. (Ed.). Cultivo de oliveira (Olea europaea L.). Pelotas: Embrapa Clima Temperado, 2009. p. 17-27. (Embrapa Clima Temperado. Sistemas de produção, 16).

COUTINHO, E. F.; JORGE, R.O.; HAERTER, J. A. Cultivares. In: COUTINHO, E. F. et.al. (Ed.). Oliveira: aspectos técnicos e cultivo no Sul do Brasil. Brasília: Embrapa, 2015. p. 57-85.

DA CROCE, D. M. et al. Avaliação da produção e do rendimento de azeite das oliveiras Arbequina, Arbosana e Koroneiki em Santa Catarina. Agropecuária Catarinense, Florianópolis, v. 29, n. 1, p. 54-57, 2016.

ELOI, L. Desafios da olivicultura no RS são debatidos em evento estadual. Pelotas, 2 dez. 2016. Disponível em: https://www.embrapa.br/climatemperado/busca-de-noticias/-/noticia/18641373/desafios-da-olivicultura-no-rs-saodebatidos-em-evento-estadual. Acesso em 25 jan. 2017.

EPAMIG. EMPRESA DE PESQUISA AGROPECUÁRIA DE MINAS GERAIS. Notícias: Dia de campo abre programação da Festa do Azeite em Maria da Fé. Belo Horizonte, 12 mar. 2019.2 Disponível em: https://epamig.wordpress.com/2019/03/12/dia-de-campo-abre-programacao-dafesta-do-azeite-em-maria-da-fe/. Acesso em: 3 abr. 2019. 
EVOOWR - WORLD RANKING OF EXTRA VIRGIN OLIVE OILS. EVOO of the year 2017. [S.I.], [2018]. Disponível em: http://www.evooworldranking.org/_EN/ran_evoo.php. Acesso em: 4 fev. 2018.

GRAZIANO DA SILVA, J. A nova dinâmica da agricultura brasileira. Campinas: Instituto de Economia/UNICAMP, 1996.

JOÃO, P. L.; ALMEIDA, G. T. F.; AMBROSINI, L. B. Nota Técnica: cadastro olivícola 2017. Porto Alegre: Secretaria da Agricultura, Pecuária e Irrigação/ Câmara Setorial das Oliveiras, 2017. Disponível em: http://www.agricultura.rs.gov.br/prooliva. Acesso em: 4 abr. 2019.

JORGE, R. O.; COUTINHO, E. F. A cultura da oliveira no mundo e no Brasil. In: COUTINHO, E. F. et.al. (Ed.). Oliveira: aspectos técnicos e cultivo no Sul do Brasil. Brasília: Embrapa, 2015. p. 13-17.

MUELLER, T. Extravirgindade: o sublime e escandoloso mundo do azeite de oliva. São Paulo: Tapioca, 2012.

PARANÁ. Secretaria da Agricultura e do Abastecimento. Instituto Paranaense de Assistência Técnica e Extensão Rural. Notícias. A oliveira pode ser opção para agricultor familiar. Curitiba, out. 2017. Disponível em: http://www.emater.pr.gov.br/modules/noticias/article.php?storyid=5302. Acesso em: 7 mar. 2018.

PROSPERATO. [Dados obtidos da página]. Caçapava do Sul, 2017. Disponível em: http://www.prosperato.com.br. Acesso em: 22 jan. 2017.

RIO GRANDE DO SUL. Decreto no 49.945, de 11 de dezembro de 2012. Cria a Câmara Setorial das Oliveiras. Diário Oficial do Estado do Rio Grande do Sul, Porto Alegre, 12 dez. 2012. v. 70, n. 238.

RIO GRANDE DO SUL. Decreto no 52.479, de 29 de julho de 2015. Institui o Programa Estadual de Desenvolvimento da Olivicultura. Diário Oficial do Estado do Rio Grande do Sul, Porto Alegre, 30 jul. 2015b. v. 73, n. 144.

RIO GRANDE DO SUL. Secretaria da Agricultura, Pecuária e Irrigação. Pró-Oliva. Antecedentes. Porto Alegre, 2015a. Disponível em: http://www.agricultura.rs.gov.br/pro-oliva. Acesso em: 8 abr. 2017.

RIO GRANDE DO SUL. Secretaria da Agricultura, Pecuária e Irrigação. Pró-Oliva. Situação Atual. Porto Alegre, 2019. Disponível em: https://www.agricultura.rs.gov.br/pro-oliva. Acesso em: 12 nov. 2019.

SAINT-HILAIRE, A. Viagem ao Rio Grande do Sul. Brasília: Senado Federal, Conselho Editorial, 2002. 575p. Disponível em: http://www2.senado.leg.br/bdsf/item/id/1064. Acesso em: 8 jul. 2016.

SANZ CAÑADA, J. et al. Multifuncionalidad y sistemas agroalimentarios locales: prioridades de investigación e innovación em medio ambiente, territorio y desarrollo 
rural en el sector español del aceite de oliva. In: INTERNATIONAL EAAE-SYAL SEMINAR, 2010, Parma. [Papers...] Parma: EEAE/SYAL, 2010.

SAUERESSIG, D. Futuro promissor para o azeite brasileiro. Revista A Granja. Porto Alegre, ํㅡㄴ 784, p. 48-50, abr. 2014.

SAUERESSIG, D. O desenvolvimento da olivicultura no Rio Grande do Sul: potencialidades e desafios. 2018. 122 f. Dissertação (Mestrado) - Programa de PósGraduação em Agronegócios, Centro de Estudos e Pesquisas em Agronegócios, Universidade Federal do Rio Grande do Sul, Porto Alegre, 2018.

SCARTON, S. Produção de azeite extravirgem deste ano deve ser a maior do estado. Porto Alegre, 15 mar. 2019. Disponível em: https://www.estado.rs.gov.br/producao-de-azeite-extravirgem-deve-ser-a-maior-dors-em-2019. Acesso em: 4 abr. 2019

VIEIRA NETO, J. et al. Botânica, descrição da planta e aspectos técnicos do cultivo da oliveira. Belo Horizonte: EPAMIG, 2008. (Circular Técnica, n. 20).

WREGE, M. S.; FILIPPINI ALBA, J. M.; COUTINHO, E. F. Clima. In: COUTINHO, E. F. et.al (Ed.). Oliveira: aspectos técnicos e cultivo no Sul do Brasil. Brasília: Embrapa, 2015. p. 19-27.

WREGE, M.; COUTINHO, E. Zoneamento agroclimático da olivicultura. In: FILIPPINI ALBA, J. M.; FLORES, C. A.; WREGE. M. S. (Ed.). Zoneamento edafoclimático da olivicultura para o Rio Grande do Sul. Brasília: Embrapa, 2013.

ZYLBERSZTAJN, D. Conceitos gerais, evolução e apresentação do sistema agroindustrial. In: ZYLBERSZTAJN, D.; NEVES. M. F. (Orgs.). Economia \& gestão dos negócios agroalimentares. São Paulo: Pioneira, 2010. Disponível em: http://pensa.org.br/category/livros-publicados/. Acesso em: 10 dez. 2017.

ZYLBERSZTAJN, D. Estruturas de governança e coordenação do agribusiness: uma aplicação da nova economia das instituições. 1995. 241 f. Tese (Livre Docência em Administração) - Departamento de Administração, Faculdade de Economia, Administração e Contabilidade, Universidade de São Paulo, São Paulo, 1995. Disponível

em:

http://www.erudito.fea.usp.br/PortalFEA/Repositorio/616/Documentos/Tese_Livre_D ocencia_DZ.pdf. Acesso em: 12 dez. 2017. 